\title{
Conclusion: Rethinking African Governance and Development
}

\author{
Richard C. Crook and David Booth
}

\begin{abstract}
This article draws together the main strands of argument being developed by the Africa Power and Politics Programme (APPP), as reflected in this IDS Bulletin. The central question is what kinds of governance arrangements work better to support the provision of the public goods that are essential to sustained and inclusive development in Africa. Evidence at local, sectoral and national levels is pointing to the overall conclusion that what works is often a 'practical hybrid', combining authoritative coordination with local problem-solving and constructive borrowing from local cultural repertoires. Consistent with the general idea of 'going with the grain', we find that the most likely source of the necessary vertical discipline is a developmental form of neo-patrimonialism, not 'good governance', as currently conceived. Similarly, local collective action to address bottlenecks in public goods provision is seldom enhanced by standard donor and NGO approaches to citizen or client empowerment.
\end{abstract}

Rethinking African governance in a development perspective is no small challenge. The research reported in this $I D S$ Bulletin seeks to illuminate what we consider one of the great issues of our time. We offer this contribution with all due modesty, and as work in progress, with a view to stimulating the debate we believe to be urgently needed.

As explained in the Introduction, current research within the Africa Power and Politics Programme (APPP) is addressing the question of 'what works?' and pursuing the idea of 'going with the grain' in half-a-dozen fields of governance for development. The articles included cover no more than half of the topics and only a fraction of the countries within the scope of the programme. They report initial findings from empirical research, which is continuing, and draw on processes of reflection which are in important respects still maturing.

As the articles show, however, it is not too soon to identify some important propositions behind which there are already solid arguments and ample evidence. We invite fellow researchers and policy practitioners to engage with us on these emerging findings. We challenge them to join us in debating the implications for development actors and for the future of Africa.
Our most important insights concern what kinds of governance work better to support the provision of the public goods that are essential to sustained and inclusive development. They are built on comparative analysis of the empirical findings from case studies of governance at three levels: local, sectoral and national.

The studies of local governance were all framed by a rigorous attempt to understand why a particular set of public goods (safe birthing, public security, public cleansing and sanitation and local markets) are delivered more successfully in some settings or places than in others. In each area of provision, the focus was on institutional configurations and their relationship to local forms of collective action, or what we term 'local problem-solving'. In most cases, service delivery was dependent on some kind of 'co-production' or multi-agency, multi-actor collaboration, with contributions from a range of state, social, private and international agencies (see Olivier de Sardan's 'The Eight Modes of Local Governance...', this IDS Bulletin).

One of the most powerful explanations of why public goods were provided relatively successfully in some places is the presence of forms of local collective action which can deal with the specific

IDS Bulletin Volume 42 Number 2 March 2011 (C) 2011 The Authors. IDS Bulletin (c 2011 Institute of Development Studies Published by Blackwell Publishing Ltd, 9600 Garsington Road, Oxford OX4 2DQ, UK and 350 Main Street, Malden, MA 02148, USA 
problems facing communities in their own ways. They work because they are locally anchored in established forms of social obligation which can sustain contributions to the public interest and thus mitigate the free-rider problem which undermines so many attempts at collective action. Thus, traders' associations in Sierra Leone were able to organise the contributions to waste management without which the City Council service could not have operated - and were able to prevent free-riding through their ability to collectively sanction members. In Niger, groups as diverse as bus owners' unions, cattle brokers, youth associations, health-user committees and savings groups have played key roles in providing resources to facilitate public security, waste management and maternal health services. In Malawi, by contrast, attempts to reduce maternal mortality by banning traditional birth attendants (TBAs) and encouraging women to attend modern clinics are failing because insufficient account has been taken of local beliefs and attitudes. There has been no action to spread the message or support the policy. The TBAs themselves have not been brought on board but continue as a counterforce, undermining official policy.

It is important, however, to distinguish these findings from what is now a conventional wisdom of development policy; the idea that better governance requires the funding and encouragement of 'associational' life (sometimes termed 'building civil society'). As the country studies show, co-production is not easily facilitated by donor-funded and inspired committees or associations conceived as formal advocacy groups in the 'Northern' mode, or as co-managers. Even democratic participation, seen as a way of arousing citizen demand for better public services, emerges from our research as a weak force at best.

The local forms of collective action which worked did not involve accountability to an abstract 'public', and did not conform to any formal financial accounting standards. The actors were more often than not quite restricted interest groups, with an incentive, i.e. a pay-off, for what they were doing, and an ability to draw upon local forms of solidarity. Their actions seldom involved 'demanding' better public services or greater accountability. Local participation in security issues, for instance, was often focused on goals and methods which would not be supported by a donor development agency, with pay-offs linked to an informal semi-privatisation of services. And the impact of multi-party competition on market management in Malawi was simply to undermine the local legitimacy and effectiveness of the formerly respected community-based market traders' committee.

A second key explanatory factor to emerge from the comparative analysis concerns the extent to which there is administrative coordination and policy coherence among the multiple agencies and actors involved. In Niger, for instance, the delivery of security by the gendarmerie was a function of coordination among the gendarmes themselves, the Prefect, private security agencies, youth militias providing Neighbourhood Watch, mayors and chiefs. And emergency maternity care has benefited from a very local coordination among clinic managers and users, local authorities and development projects. But conflicts of jurisdiction and lines of accountability, together with multiple funding sources made the delivery of some services extremely difficult, as it does in so many other settings in Africa. In Malawi, maternal health was affected by a basic failure to anticipate how the policy reform was likely to play out in practice. As Olivier de Sardan reminds us, ensuring the needed coordination is not easy in the general absence of strong central government agencies and other overarching authorities. Being dependent on informal arrangements and the 'good will' not just of social actors but also of officials in state and local government positions and donor projects makes coordination haphazard and fragile.

Such problems are linked to a third key element in the successful provision of public goods: the presence of authorities capable of imposing rule enforcement and discipline within public organisations and among service providers. To have a generalised effect, this must stem from the national political system. Our comparative analysis of neo-patrimonial regimes, discussed below, says something about the conditions under which this is likely. But the necessary discipline may not have to come from central government agencies if other public or collective 'authorities' are present locally. In Sierra Leone, sanctions to enforce the behaviour required to sustain public cleanliness of the market were 
provided largely through associational 'selfregulation'. In contrast, the provision of clean meat was not assured because self-regulation could not make up for the absence of any will or capacity to enforce regulations on the part of the City Council or higher government authorities. The latter failure was linked to the perverse effects of donor-driven funding incentives. Malawi presents an even stronger set of contrasting examples, where on the one hand security provision was improved through the exercise of strong authority by the administration and the police in collaboration with local government and local associations, while market management faltered because of conflicts over authority to regulate and enforce, caused by party-politicisation.

Some of the explanatory factors from the local governance work also feature in APPP's sectoral studies of forestry services, educational reform, cotton marketing and local justice. Only the justice study, focused on dispute settlement institutions (DSIs) in Ghana, has been presented in this collection. This concerns the provision of a fundamental public good (legitimate and accessible justice) by state agencies, or those supported by the state, at the local level. Two aspects of the findings are worth emphasising here.

First, the ability to be responsive to local cultures - i.e. anchor ways of settling disputes in local concepts of fairness - was found to be an important dimension of the provision of justice by the three DSIs in Ghana. However, this ability was a function of the discipline and coordination to which they were subject as instances of national organisations. This may seem paradoxical, but the legitimacy and popularity of the magistrate's courts and the CHRAJ district mediations were linked in a very material way to their being part of well-established and autonomous state bodies. The professionalism and commitment of their staff underpinned their reputation for neutrality. And their ability to offer enforceable and/or authoritative remedies also derived from the power of the state, as articulated through the Judicial Service and the national organisation of the CHRAJ. The Customary Land Secretariats, on the other hand, suffered from a lack of clarity over what procedures or codes to follow and because of their 'traditional' character were actually more likely to be formalistic and less attuned to local values. And because they were embedded in local political hierarchies and power struggles, they were less likely to be seen as impartial - the key feature of local beliefs about justice.

Second, the flexibility of the way the more successful DSIs worked may be attributed to their 'hybridity'; they combined commitment to certain formal laws, procedures and codes with practices which responded to their local situations: the use of local languages, informal discourses and codes, which enabled individual officers to deal with the realities of life as presented to their institutions on a daily basis. These informal behaviours, however, were always framed within the core disciplines imposed by their organisation. These organisations indeed authorised some of their experiments with informality through the new court-attached Alternative Dispute Resolution (ADR) system and of course the whole ADR approach of the CHRAJ district mediators. This is something echoed in other APPP research findings at the sector level, as well as in some of the local governance work. Successful managers of underresourced public services adapt to local life while retaining their core mission and authority.

The policy implications of these findings are very strong, although not necessarily easy to accept. International organisations, donors and NGOs should support authoritative coordination and the pursuit of policy coherence by African governments, and avoid the conflicts of jurisdiction and operational philosophy which frequently emerge from separately funded initiatives and changing global priorities. Associations and committees created according to funders' blueprints should be avoided in the interests of genuine collective action. Greater recognition is needed that 'what works' may be rooted in very localised and complex ways of doing things which coexist within forms of governance which, out of necessity, are informalised and penetrated by local arrangements and pay-offs, deals and political clientelism. In these senses, the governance arrangements that support development best at the local level may not resemble any current notions of 'good governance'. This is not to say that anything goes. On the contrary, a key ingredient of success, when an effective way has been found to deliver a particular public good, is 
a minimum of rule enforcement within and on the part of provider organisations. This may be achieved by self-regulation if and when the providers themselves have some corporate discipline, as in the case of the transport unions. Otherwise, it will depend on the extent to which vertical coordination is supported politically at the national level.

At the national level, as at the sectoral and local levels, what works does not seem to be 'good governance' as is currently understood. Our comparative work on neo-patrimonial regimes shows very clearly that it is possible for a government to pursue successful developmental policies within a political system which operates primarily on the basis of patron-client relations and thus 'goes with the grain' of the dominant mode of state-society interaction.

The articles included in this IDS Bulletin propose a preliminary theory for categorising and explaining the differences among neopatrimonial regimes. How is it that in some states 'patronage politics' seems to produce only predation and economic collapse, while in others the outcomes justify the use of the term 'developmental patrimonialism'? Kelsall suggests that the key factors are a combination of the extent to which rent extraction is centralised under the control of the ruler, and the extent to which the capital generated by such rental extraction is invested in more long-term, productive projects or enterprises. The most benign combination occurs when there is fully centralised rent control under a unified elite, and long-horizon investment of rents.

Developmental outcomes follow because such a regime demands and sustains a competent public service which is vertically disciplined (with authority ultimately derived from the political regime) but also given sufficient autonomy to manage and implement development policies - it therefore has 'bureaucratic integrity'.

Examples of such regimes in Africa include Côte d'Ivoire under President Houphouet-Boigny until the late 1970s, Botswana, Kenyatta's Kenya, Rwanda since 2000 and the case examined in detail here, Malawi under President Banda up to 1979 and under President Mutharika until 2009.

The Malawi material illustrates very powerfully the way in which changes in these combinations of factors affected developmental outcomes over a period of 45 years. The impact of multi-party politics was particularly striking in the context of a weak regime struggling to establish control; short-termism, an explosion of corruption and a collapse in civil service morale and discipline led to real declines in policymaking capacity and a severe deterioration in economic performance. Yet this was neither permanent nor an inevitable consequence of 'democracy' as such; the emergence of a more powerful centralising political regime under Mutharika enabled some rebuilding of the technocracy and policy capacity with consequent improvements in outcomes.

What Malawi also shows us, however, is that even the most developmental regimes in this model may bear little relation to what might be termed 'good governance'. Even although Banda was tough on corruption, the patronage system enabled the emergence of a powerful group of party loyalists and civil servants who became successful business entrepreneurs through the policy of encouraging estate agriculture. Banda's own company, Press Holdings, became a major conglomerate which came to play an important and effective - role in the economic strategy.

Thus, patronage remained at the core of a system of state-business relations which did create some successful developmental outcomes. This increased prosperity was translated into better public services for the population because of the effectively disciplined public bureaucracy.

This theoretical distinction between developmental and predatory neo-patrimonialism builds on and modifies previous 'developmental state' models. Over a decade ago, Peter Evans posed the question of whether it was possible to envisage developmental states of the East Asian type emerging in other poor countries such as those of sub-Saharan Africa, but without resorting to a naive voluntarism about how policymakers could help to 'construct' such states (Evans 1998). It is now evident that the real problem is to understand the conditions under which certain kinds of political regime are likely to generate developmental technocracies, given that the East Asian - and to a lesser extent South-East Asian stories were so specific to their place and time context. Our model suggests that a theory centred on autonomous state bureaucracies embedded in business networks does not travel well to the African context. Successful African regimes seem 
to have created their own business and investment economies through the logic of a state-driven demand for long-term returns to patronage-based enterprises. And to ensure this, they demand not autonomous 'Weberian' bureaucracies, but bureaucracies that are competent and disciplined, yet dedicated to implementing the projects of the political elite.

Whether such regimes can be promoted or built through deliberate policy action requires further discussion. In the present era, it is politically difficult for Northern donors to support what might be termed benign despotisms, even in the shape of dominant party regimes masquerading as multi-party democracies. Yet the evidence for Africa suggests that the expected longevity of a regime, when combined with the characteristics of a developmental patrimonialism, is an underappreciated factor working in favour of what is known in the aid business as 'country-owned development effort'. Certainly, it is hard to visualise equivalent results being generated under systems of competitive democracy in which incumbents face the actuality or risk of loss of office at frequent intervals, powerfully incentivising them to engage in short-term

\section{Reference}

Evans, P. (1998) 'Transferable Lessons? Reexamining the Institutional Prerequisites of East Asian Economic Policies', Journal of Development Studies 34.6: 66-85 pillage of public resources. In any case, development agencies have to work with the realities of country governance as they find them - experience does not suggest that developmental governance can be purchased with funding and conditionalities. That being the case, our analysis may at least provide a more convincing rationale for some of the things that donors are already doing for pragmatic reasons in some countries.

Overall, our research is suggesting that the institutions most likely to contribute to development in low-income Africa are 'practical hybrids', combining the authoritative coordination which can come from a developmental neo-patrimonial state with an enabling environment for local problem-solving and a constructive use of culturally legitimate ways of working. This contrasts sharply with conventional 'good governance'. It also represents a significant departure from the Evans concept of the developmental state in giving less emphasis to bureaucratic autonomy, more prominence to differences among political regime types and a much more encompassing role to social embeddedness. 